\title{
Searching for common threads in threadfins: phylogeography of Australian polynemids in space and time
}

\author{
John B. Horne ${ }^{1, *}$, Paolo Momigliano ${ }^{1,2}$, David J. Welch ${ }^{3,5}$, Stephen J. Newman ${ }^{4}$, \\ Lynne van Herwerden ${ }^{1}$
}

\author{
${ }^{1}$ School of Tropical and Marine Biology, Molecular Ecology and Evolution Laboratory, \\ and ${ }^{3}$ Fishing and Fisheries Research Centre, School of Earth and Environmental Sciences, James Cook University, \\ Townsville, Queensland 4811, Australia \\ ${ }^{2}$ Australian Institute of Marine Science, PMB No. 3, Townsville, Queensland 4810, Australia \\ ${ }^{4}$ Western Australian Fisheries and Marine Research Laboratories, Department of Fisheries, \\ Government of Western Australia, PO Box 20, North Beach, Western Australia 6920, Australia \\ ${ }^{5}$ Queensland Primary Industries and Fisheries, Department of Employment, Economic Development and Innovation,
} PO Box 1085, Oonoonba, Queensland 4811, Australia

\begin{abstract}
Proper management of marine fisheries requires an understanding of the spatial and temporal dynamics of marine populations, which can be obtained from genetic data. While numerous fisheries species have been surveyed for spatial genetic patterns, temporally sampled genetic data is not available for many species. We present a phylogeographic survey of the king threadfin Polydactylus macrochir across its species range in northern Australia and at a temporal scale of 1 and 10 yr. Spatially, the overall AMOVA fixation index was $\Phi_{\mathrm{st}}=0.306\left(F_{\mathrm{st}}^{\prime}=0.838\right), \mathrm{p}<0.0001$ and isolation by distance was strong and significant $\left(\mathrm{r}^{2}=0.45, \mathrm{p}<0.001\right)$. Temporally, genetic patterns were stable at a time scale of $10 \mathrm{yr}$. However, this did not hold true for samples from the eastern Gulf of Carpentaria, where populations showed a greater degree of temporal instability and lacked spatial genetic structure. Temporal but not spatial genetic structure in the Gulf indicates demographic interdependence but also indicates that fishing pressure may be high in this area. Generally, genetic patterns were similar to another co-distributed threadfin species Eleutheronema tetradactylum, which is ecologically similar. However, the historical demography of both species, evaluated herein, differed, with populations of $P$. macrochir being much younger. The data are consistent with an acute population bottleneck at the last glacio-eustatic low in sea level and indicate that the king threadfin may be sensitive to habitat disturbances.
\end{abstract}

KEY WORDS: Australia · Pelagic larvae · Self-recruitment · Metapopulation · Genetic drift Polydactylus macrochir

Resale or republication not permitted without written consent of the publisher

\section{INTRODUCTION}

Populations of benthic marine organisms, such as many marine fishes, are often described as metapopulations (Kritzer \& Sale 2006), where reproductive adults form isolated sub-populations (called stocks by fisheries biologists) that exchange migrants via a dis- persive pelagic larval phase. Although relatively short in duration, the events that take place during the pelagic larval phase are critical in determining the geographic boundaries of marine populations. For this reason, larval mediated migration has long been an important area of marine biology and is relevant to studies on speciation, ecology, fisheries biology and 
conservation biology of marine organisms (Planes 2002, Cowen et al. 2007, Hellberg 2007, 2009, Jones et al. 2009). Yet, there are many logistical challenges to studying the movements of tiny oceanic larvae, including the extreme spatial scale at which dispersal can take place, and the complex influences of physical properties of the ocean on larval dispersal (Siegel et al. 2008, Cowen \& Sponaugle 2009), which all but prevent direct observations of connectivity. Therefore, much of what we know about pelagic larval dispersal comes from indirect genetic approaches (Planes 2002, Hellberg et al. 2002, Hellberg 2007, 2009, Hedgecock et al. 2007, Jones et al. 2009, Leis et al. 2011).

The delineation of fish stocks through genetic approaches, such as phylogeography and population genetics, is particularly important for the effectiveness of fisheries management and conservation strategies, provided that genetic patterns can be interpreted correctly (Waples 1998). While genetic data is highly sensitive to migration and the movement of genes between areas at some point in time, it often fails to indicate whether connectivity is demographically significant, i.e. it has a meaningful effect on the size and persistence of populations (Waples \& Gaggiotti 2006, Lowe \& Allendorf 2010). Therefore, care must be taken to determine whether genetic patterns represent contemporary (ecological) patterns of gene flow and if so, whether gene flow is high enough to be demographically significant (Hauser \& Carvalho 2008, Waples et al. 2008, Selkoe et al. 2008). Conversely, however, while genetic connectivity does not necessarily suggest demographic connectivity, significant genetic structure between populations is an indication that any larval migrant exchange between stocks is of little consequence demographically (Avise 2000). Therefore, genetic population structure is typically a more informative pattern than genetic population connectivity.

Small \& Wares (2010) explain that the genetic structure of marine populations, in which larvae are subject to advection by oceanographic processes, can only be maintained where retention of locally produced larvae exceeds larval displacement (see also Pringle \& Wares 2007). In other words, genetic structure implies substantial local recruitment, but also suggests that self-sustaining populations may act as important sources of migrants to downstream areas, making structured populations potential management priorities. Recently, Horne et al. (2011) reported this pattern in a tropical inshore marine fish, the blue threadfin Eleutheronema tetradactylum (Polynemidae) in northern Australia. Significant genetic structure was sometimes detected at very small spatial scales in this species, in spite of having larvae with limited swimming and sensory capabilities that might preclude self-recruitment, suggesting the need for local scale management.

The results of Horne et al. (2011) provide valuable insight into the small-scale demographics of a commercially important fish that in the past has been managed as a single stock. However, one limitation of the Horne et al. (2011) paper is that the time scale of sampling was very short and the temporal stability of the observed spatial genetic structure is unknown. Understanding the temporal stability of demographic processes, such as recruitment and dispersal, is vital to the long-term management of fish stocks. Yet few genetic studies account for temporal heterogeneity of spatial genetic patterns (Hedgecock et al. 2007, Selkoe et al. 2008), which is unfortunate because marine population dynamics may be highly variable in time as well as space (Siegel et al. 2008). In fact, considering the advective nature of marine environments and the potential for pelagic larval dispersal, population structure along ocean coastlines is not at all intuitive (Pringle \& Wares 2007), may be ephemeral, and theoretically should not persist without strong biotic and or abiotic influences. Therefore, temporally sampled data are desirable for understanding the demographic stability of marine populations, at least at the time-scale at which sampling takes place.

Comparative phylogeography is another way to determine the temporal stability of genetic structure. Congruent spatial genetic structure observed across multiple co-occurring taxa demonstrates that genetic patterns are due to the influences of the physical environment over long periods of time rather than other confounding effects (Kuo \& Avise 2005). The purpose of this paper is to provide a comparative context to the results of Horne et al. (2011) and to further investigate demographic patterns of threadfin fishes for fisheries management purposes. To this end, we present a phylogeographic study of another inshore marine Polynemid, the king threadfin Polydactylus macrochir, formerly Polynemus sheridani (Motomura et al. 2000), across northern Australia. P. macrochir co-occurs with Eleutheronema tetradactylum and is a large estuarine-associated species that has been known to reach $1.7 \mathrm{~m}$ in length and weigh over $40 \mathrm{~kg}$ (Motomura 2004). Like E. tetradactylum, P. macrochir is a protandrous hermaphrodite that spawns pelagic eggs and larvae. The pelagic larval duration of this species is not known, but given the mode of reproduction it is presumed to have a high dispersal potential. Its large size makes $P$. macrochir an attractive food fish, and it is targeted by anglers and indigenous 
fishers in northern Australia and southern New Guinea, where this species is endemic. P. macrochir also supports a sizeable commercial fishery (Welch et al. 2002, 2005) but management of this fishery has heretofore not been based on empirically acquired information.

Drawing on a previous phylogeographic study of Polydactylus macrochir by Chenoweth \& Hughes (2003), we were able to acquire temporally sampled data for this species in some areas. The sampling interval between the 2 studies is $\sim 10 \mathrm{yr}$ (1998 to $2008 / 2009$ ), allowing us to observe genetic patterns at a time scale beyond that of most phylogeographic investigations. P. macrochir generally does not live $>10$ yr (Welch et al. 2010), although in some areas it can attain a lifespan of $>20 \mathrm{yr}$ (Moore et al. 2011). However, while the temporal scale of our analysis is within the maximum lifespan range of the species, hereafter we show that this is still sufficient time to observe genetic population turnover.

\section{MATERIALS AND METHODS}

\section{Sampling}

A total of 467 adult Polydactylus macrochir were sampled across northern Australia from 4 different regions: east Queensland coast (EQldC), east Gulf of Carpentaria (EGoC), Northern Territory (NT) and northwest Western Australia (NWWA). Within each region 2 or 3 locations were sampled (Fig. 1; Table 1). Samples were obtained from commercial fishing activities and collected by fishermen using monofilament gillnets. Fin clips were taken from individuals at each location and stored in a salt-saturated $20 \%$ di-methyl sulfoxide buffer with $0.25 \mathrm{M}$ EDTA or $80 \%$ ethanol. Sampling was carried out in 2 consecutive years, 2008 and 2009 (hereafter Years 1 and 2). Three locations, each from a different region, were sampled in both Years 1 and 2 in order to test the temporal stability of

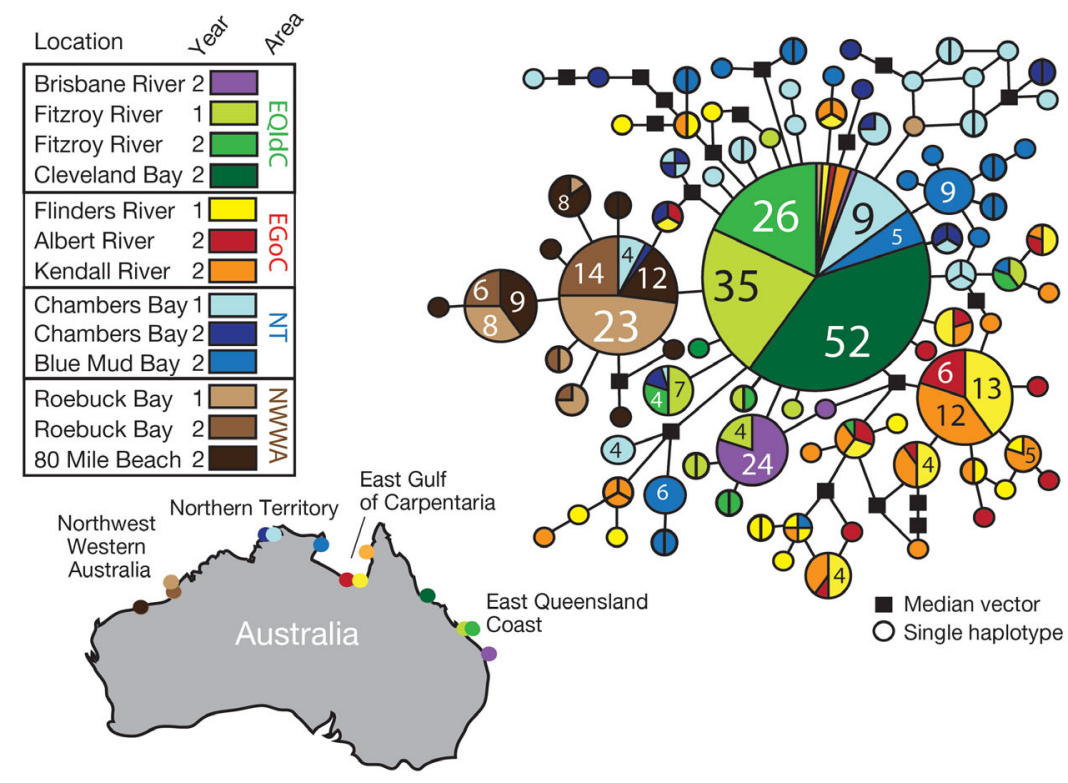

Fig. 1. Polydactylus macrochir. Minimum spanning network of 467 individual mitochondrial control region haplotypes. Samples were collected in 2008 (Year 1) and 2009 (Year 2) from locations in 4 regions across northern Australia: East Queensland coast (EQldC), Eastern Gulf of Carpentaria (EGoC), Northern Territory (NT) and northwest Western Australia (NWWA)

Table 1. Polydactylus macrochir. Sample sizes (n) and diversity indices: number of haplotypes, haplotype diversity $(h)$, and nucleotide diversity $(\pi)$; for all regions and populations

\begin{tabular}{|lrrrr|}
\hline & $\mathrm{n}$ & $\begin{array}{c}\text { No. of } \\
\text { haplotypes }\end{array}$ & $h$ & $\pi$ \\
\hline East Queensland Coast (EQldC) & $\mathbf{1 6 2}$ & $\mathbf{1 1}$ & $\mathbf{0 . 4 9}$ & $\mathbf{0 . 0 0 1 9}$ \\
Brisbane River 2 (BR) & 25 & 3 & 0.22 & 0.0007 \\
Fitzroy River 1 (FzR 1) & 50 & 7 & 0.49 & 0.0020 \\
Fitzroy River 2 (FzR 2) & 35 & 6 & 0.47 & 0.0024 \\
Cleveland Bay 2 (ClB) & 52 & 1 & 0.00 & 0.0000 \\
East Gulf of Carpentaria (EGoC) & $\mathbf{1 1 6}$ & $\mathbf{3 0}$ & $\mathbf{0 . 8 6}$ & $\mathbf{0 . 0 0 8 3}$ \\
Flinders River 1 (FlR) & 49 & 21 & 0.91 & 0.0097 \\
Albert River 2 (AlR) & 21 & 13 & 0.91 & 0.0080 \\
Kendall River 2 (KeR) & 46 & 16 & 0.87 & 0.0070 \\
Northern Territory (NT) & $\mathbf{9 5}$ & $\mathbf{3 4}$ & $\mathbf{0 . 9 3}$ & $\mathbf{0 . 0 0 9 9}$ \\
Chambers Bay 1 (ChB 1) & 41 & 19 & 0.92 & 0.0083 \\
Chambers Bay 2 (ChB 2) & 21 & 13 & 0.93 & 0.0113 \\
Blue Mud Bay 2 (BMB) & 33 & 11 & 0.83 & 0.0079 \\
Northwest Western Australia (NWWA) & $\mathbf{9 4}$ & $\mathbf{1 2}$ & $\mathbf{0 . 6 5}$ & $\mathbf{0 . 0 0 2 6}$ \\
Roebuck Bay 1 (RbB 1) & 39 & 7 & 0.58 & 0.0022 \\
Roebuck Bay 2 (RbB 2) & 22 & 4 & 0.54 & 0.0018 \\
Eighty Mile Beach 2 (EMB) & 33 & 7 & 0.76 & 0.0036 \\
Total & $\mathbf{4 6 7}$ & $\mathbf{7 4}$ & $\mathbf{0 . 8 7}$ & $\mathbf{0 . 0 0 7 2}$ \\
\hline
\end{tabular}

the genetic patterns. We also compare our sequences to those from Chenoweth \& Hughes (2003), all of which were collected in 1998 or earlier. Therefore, we assessed the genetic structure of $P$. macrochir at the spatial scale of northern Australia and a temporal scale of 1 and $10 \mathrm{yr}$. 


\section{Laboratory methods}

The mitochondrial control region was amplified using the following primer sequences: $\mathrm{MT} 16498 \mathrm{H}_{\text {; }}$ 5'-CCT GAA GTA GGA ACC AGA TG-3' and Pro-L; 5'-CTA CCT CCA ACT CCC AAA GC-3' (Meyer et al. 1990, Palumbi et al. 1991) as referenced by Chenoweth \& Hughes (2003). PCR was carried out in $20 \mathrm{\mu l}$ reactions using: $2.5 \mathrm{mM}$ Tris $-\mathrm{Cl}(\mathrm{pH} 8.7), 5 \mathrm{mM}$ $\mathrm{KCl}, 5 \mathrm{mM}\left(\mathrm{NH}_{4}\right)_{2} \mathrm{SO}_{4}, 200 \mu \mathrm{M}$ each dNTP, 2.5-3.5 $\mathrm{mM} \mathrm{MgCl} 2,10 \mu \mathrm{M}$ each primer and $1 \mathrm{U}$ of Taq Polymerase (Qiagen). Thermocycling was carried out with an initial denaturation of $94^{\circ} \mathrm{C}$ for $2 \mathrm{~min}, 35$ cycles of denaturation, annealing and extension $\left(94^{\circ} \mathrm{C}\right.$ for $30 \mathrm{~s}, 55^{\circ} \mathrm{C}$ for $30 \mathrm{~s}, 72^{\circ} \mathrm{C}$ for $\left.90 \mathrm{~s}\right)$ and a final extension of $72^{\circ} \mathrm{C}$ for $10 \mathrm{~min}$. PCR products were confirmed by gel electrophoresis on $1.5 \%$ agarose gels and purified by either a standard isopropanol purification or an ammonium acetate ethanol clean-up. PCR products were sequenced with the mt16498H primer using Applied Biosystems technologies by Macrogen sequencing service, Seoul. We also sequenced a segment of the mitochondrial Cytochrome Oxidase subunit 1 (COI) gene region for a small subset of samples from each region $(n=18)$ using the universal COI primers for fish, Fish-F1 and Fish-R1, of Ward et al. (2005). Parameters for PCR and subsequent processing of samples were identical to those described for the control region. However, there were no sequence polymorphisms detected in $582 \mathrm{bp}$ of the COI region and no further investigation of this marker was conducted. DNA sequence data from this study is made publicly accessible through GenBank accession numbers JQ068265-JQ068731 and through the Dryad repository (doi:10.5061/dryad. n8234tb1).

\section{Data analysis}

Raw DNA sequences were compiled in BIOEDIT version 7.0 (Hall 1999) and aligned using CLUSTAL W (Thompson et al. 1994) implemented in BIOEDIT. Sequences were then further aligned by hand. Molecular diversity indices, haplotype diversity (h) and nucleotide diversity $(\pi)$ of control region sequences were calculated in DNAsp v. 5.10 (Librado \& Rozas 2009). A visual representation of the control region haplotypes and their respective frequencies, in the form of a haplotype network, was constructed using TCS (Clement et al. 2000). Spatial genetic structure of populations was assessed by way of analysis of molecular variance (AMOVA) performed in ARLE-
QUIN 3.5 (Excoffier \& Lischer 2010). Overall AMOVA fixation indices $\left(\Phi_{\mathrm{st}}\right)$ and pairwise fixation indices $\left(F_{\text {st }}\right)$ were computed using 10000 permutations. DNA sequence data was also converted into haploid gene frequencies and recoded in RECODEDATA v. 0.1 (Meirmans 2006) to calculate $F_{\text {st }}(\max )$. Raw $F_{\text {st }}$ divided by $F_{\text {st }}(\max )$ yields a standardized index $\left(F^{\prime}{ }^{\prime} \mathrm{t}\right)$, which is unbiased by within-population variation. Values of $F_{\text {st }}$ and $F^{\prime}$ st were also calculated between the recently collected Polydactylus macrochir from this study and the data from Chenoweth \& Hughes (2003) in order to assess the temporal stability of haplotype frequencies. The relationship between genetic structure of populations and geographic distance, isolation-by-distance (IBD), was performed online using IBD web service using 10000 randomizations of the data (Jensen et al. 2005). The geographic distances used for IBD were the approximate linear shoreline distances between sampled populations, estimated in kilometers using Google Earth version 4.3 ; these were compared to corresponding pairwise genetic distance $\left(F_{\mathrm{st}} /\left(1-F_{\mathrm{st}}\right)\right.$ (Rousset 1997).

\section{Historical demography}

The historical demography of Polydactylus macrochir and Eleutheronema tetradactylum (COI data from Horne et al. 2011) was initially explored using Fu's Fs test of selective neutrality, which is a highly sensitive test of population expansion (Fu 1997, Ramos-Onsins \& Rozas 2002) and mismatch distributions (Rogers \& Harpending 1992) calculated in ARLEQUIN with 10000 permutations for both species. In the case of an expanding population, the crest of the mismatch distribution indicates the time since expansion began in generational units $(\tau)$. As time progresses, the crest of the distribution moves to the right at a rate of 1 unit every $1 / 2 u$ generations, where $u=2 \mu k$, and $\mu$ is the neutral substitution rate per site multiplied by the generation time and $k$ is the number of nucleotide sites (Rogers \& Harpending 1992). Expansion time $(t)$ can therefore be calculated as $t=(\tau / 2 u) \times$ generation time (Rogers \& Harpending 1992).

Reconstructions of historical demography were also carried out in LAMARC v. 2.1.5 (Kuhner 2006), using Bayesian coalescent simulations, which estimates 3 different demographic parameters:

(1) $\Theta$, which for mtDNA is interpreted as $2 N_{\mathrm{ef}} \mu$, where $N_{\text {ef }}$ is the effective number of females in the population. $\Theta$ was estimated under the assumption of 
unconstrained population growth as well as constant population size (growth $=0$ )

(2) The exponential growth parameter $g$ (in units of $1 / \mu)$

(3) Migration rate $M$, where the number of migrants from one population to another $\left(N \mathrm{~m}_{\mathrm{ij}}\right)$ is equal to $\Theta_{\mathrm{i}} \times M_{\mathrm{ij}}$ for mtDNA.

All parameters were calculated using a reduced data set of 30 randomly chosen individuals, to improve the computation time (Felsenstein 2006, Kuhner 2009). All 3 parameters were evaluated using a Bayesian search strategy. Each run consisted of one short and one long Markov chain Monte Carlo (MCMC) and 5 thermodynamically heated Markov coupled Markov chain Monte Carlos (MCMCMC), which ran for a total of $20 \times 10^{6}$ generations, sampling every 20 generations with a $20 \%$ burn-in. Control region sequences of Polydactylus macrochir were run under the F84 substitution model, using a transition-transversion ratio of 14.548 , as estimated in jMODELTEST 0.1.1 (Posada 2008). COI sequences of Eleutheronema tetradactylum were run under the GTR substitution model, with a user specified rate matrix suggested by jMODELTEST. Final values for each parameter were averaged over 10 independent runs, each with a random starting seed. Outputs from all LAMARC runs were inspected for effective sample size (ESS) in TRACER (Rambaut \& Drummond $2007)$ to determine how well the analysis was able to explore the parameter space.

Coalescence time for each species was estimated using the formula $\Theta_{t}=\Theta_{\text {now }}{ }^{-(g p) t}$, where $\Theta$ is the product of effective female population size and mutation rate at a given point in time $(t)$ and at the presenttime (now). Under the assumption of unconstrained population growth, coalescence was presumed when $\Theta_{t}=1 \%$ of $\Theta_{\text {now }}$, following the methods of Wares \& Cunningham (2001). For Polydactylus macrochir, Chenoweth \& Hughes (2003) report a substitution rate of 7.7 to $16.8 \%$ per $10^{6} \mathrm{yr}$ and a female generation time of $5 \mathrm{yr}$. Here we use the same substitution rate and generation time $\left(\mu=1.9\right.$ to $\left.4.2 \times 10^{-7}\right)$. However, given that $P$. macrochir change sex from male to female between 3 and $9 \mathrm{yr}$ of age and may sometimes live in excess of $20 \mathrm{yr}$ (Motomura 2004), we note that the average female generation time may be longer (see 'Discussion').

Coalescence age for Eleutheronema tetradactylum was based on an average female generation time of $4.5 \mathrm{yr}$, taking into account that sex change occurs at about $2 \mathrm{yr}$ of age and maximum age is $\sim 7 \mathrm{yr}$ (Motomura 2004). There is no molecular clock calibration for the COI marker from the Polynemidae, but a gen- eral substitution rate of $1.2 \%$ per $10^{6} \mathrm{yr}$ is estimated for COI, based on nucleotide divergence of geminate marine teleosts separated across the Isthmus of Panama (Bermingham et al. 1997). It is also possible that the substitution rate for COI for fish is closer to $0.5 \%$ (Knowlton \& Weigt, 1998). For the purposes of this study the COI substitution rate for E. tetradactlyum is 0.5 to $1.2 \%$ per million years ( $\mu=1.1$ to $2.7 \times 10^{-8}$ ).

\section{RESULTS}

A total of $333 \mathrm{bp}$ of the mitochondrial control region were resolved for 467 individual Polydactylus macrochir sampled across northern Australia. Out of $333 \mathrm{bp}$, a total of 65 variable sites were observed. Of these, 47 were parsimony informative, while 18 were singletons. In total 74 control region haplotypes were identified (Fig. 1). Haplotype (h) and nucleotide $(\pi)$ diversities were respectively 0.874 and 0.00715 . Genetic diversity of individual populations is reported in Table 1.

\section{Population structure}

The overall population structure was $\Phi_{\mathrm{st}}=0.306$ $\left(F^{\prime}{ }^{\prime}=0.838\right), \mathrm{p}<0.0001$ and the majority of pairwise population comparisons were significant (Table 2). The strongest pairwise fixation indices in the data set appear to be between NWWA and the rest of the sampled range, congruous with a strong east-west phylogeographic break seen in Eleutheronema tetradactylum (Horne et al. 2011). There was extremely deep population structure observed between the Brisbane River and all other populations, which like NWWA is on the periphery of the geographic distribution and may be thus isolated (Hellberg 2006). In the Gulf of Carpentaria, strong population structure was detected between Blue Mud Bay in the west gulf (NT) and populations in the EGoC. Conversely, all of the EGoC populations were spatially unstructured, indicating high connectivity within this region.

IBD analysis was positive and significant $\left(\mathrm{r}^{2}=0.45\right.$, $\mathrm{p}<0.001$ ) (Fig. 2), suggesting that connectivity between populations of Polydactylus macrochir is limited and that migrants are exchanged in a stepping stone fashion. This is in contrast to Chenoweth \& Hughes (2003), who reported a negative relationship between geographic and genetic distance at the largest spatial scale, driven by non-significant $F_{\text {st }}$ values between the Fitzroy River (EQldC) and Darwin 
Table 2. Polydactylus macrochir. Pairwise fixation indices $\left(F_{\mathrm{st}}\right)$ (lower diagonal) and standardized fixation indices $\left(F_{\mathrm{st}}{ }^{\prime}\right)(\mathrm{upper}$ diagonal) for sampled populations (name codes see Table 1). Significant values in bold. $\mathrm{f}$ : samples not significant after Bonferroni correction $(\alpha=0.00064)$

\begin{tabular}{|c|c|c|c|c|c|c|c|c|c|c|c|c|c|}
\hline & $\mathrm{BR}$ & FzR1 & FzR2 & $\mathrm{ClB}$ & FlR & AlR & $\mathrm{KeR}$ & ChB1 & ChB2 & $\mathrm{BMB}$ & $\mathrm{RbB1}$ & $\mathrm{RbB} 2$ & EMB \\
\hline BR & & 0.935 & 0.984 & 0.996 & 0.998 & 0.997 & 0.997 & 0.989 & 0.990 & 1.000 & 1.000 & 1.000 & 1.000 \\
\hline FzR1 & 0.575 & & 0.006 & 0.246 & 0.967 & 0.927 & 0.928 & 0.561 & 0.601 & 1.000 & 0.974 & 1.000 & 1.000 \\
\hline FzR2 & 0.593 & -0.005 & & 0.282 & 0.962 & 0.919 & 0.923 & 0.558 & 0.594‡ & 1.000 & 0.979 & 1.000 & 1.000 \\
\hline $\mathrm{ClB}$ & 0.924 & 0.071 & 0.063 & & 0.983 & 0.973 & 0.965 & 0.776 & 0.889 & 1.000 & 0.991 & 1.000 & 1.000 \\
\hline FlR & 0.368 & 0.261 & 0.220 & 0.291 & & 0.000 & 0.000 & 0.955 & 0.952 & 0.979 & 1.000 & 1.000 & 1.000 \\
\hline AlR & 0.494 & 0.370 & 0.310 & 0.467 & -0.015 & & 0.000 & 0.896 & 0.880 & 1.000 & 0.996 & 1.000 & 1.000 \\
\hline $\mathrm{KeR}$ & 0.410 & 0.291 & 0.248 & 0.332 & -0.004 & -0.019 & & 0.901 & 0.907 & 0.979 & 0.992 & 1.000 & 1.000 \\
\hline ChB1 & 0.352 & 0.069 & 0.053 & 0.081 & 0.198 & 0.224 & 0.213 & & 0.000 & 1.000 & 0.789 & 0.823 & 0.801 \\
\hline ChB2 & 0.360 & 0.077 & 0.052‡ & 0.118 & 0.176 & 0.191 & 0.197 & -0.002 & & 1.000 & 0.893 & 0.916 & 0.903 \\
\hline BMB & 0.358 & 0.186 & 0.155 & 0.218 & 0.213 & 0.230 & 0.229 & 0.120 & 0.107 & & 1.000 & 1.000 & 1.000 \\
\hline RbB1 & 0.774 & 0.580 & 0.556 & 0.748 & 0.400 & 0.504 & 0.444 & 0.319 & 0.331 & 0.382 & & 0.000 & $0.241 \mathrm{I}$ \\
\hline $\mathrm{RbB2}$ & 0.831 & 0.627 & 0.600 & 0.858 & 0.378 & 0.476 & 0.424 & 0.316 & 0.313 & 0.357 & -0.021 & & 0.250 \\
\hline EMB & 0.716 & 0.560 & 0.532 & 0.700 & 0.391 & 0.469 & 0.431 & 0.327 & 0.322 & 0.372 & 0.042干 & 0.027 & \\
\hline
\end{tabular}

Harbor (NT). In the present study we also report weak genetic structure between NT and the Fitzroy River. However, our sampling extended beyond the range of Chenoweth \& Hughes (2003) and strong genetic structure was observed between the most distant populations, reaffirming IBD. When NT populations and Cleveland Bay (EQldC) populations are removed from the analysis, the signal of IBD was much stronger and similar to that reported for mtDNA in Eleutheronema tetradactylum $\left(\mathrm{r}^{2}=0.62\right.$, $\mathrm{p}<0.001)$.

Temporally, $F_{\text {st }}$ values between samples from the current study and those collected $>10$ yr earlier by Chenoweth \& Hughes (2003) were not significant for the same locations, such as the Fitzroy River (Table 3). Darwin Harbor and Chambers Bay also share a close proximity and are temporally unstructured. Yet samples collected a decade apart

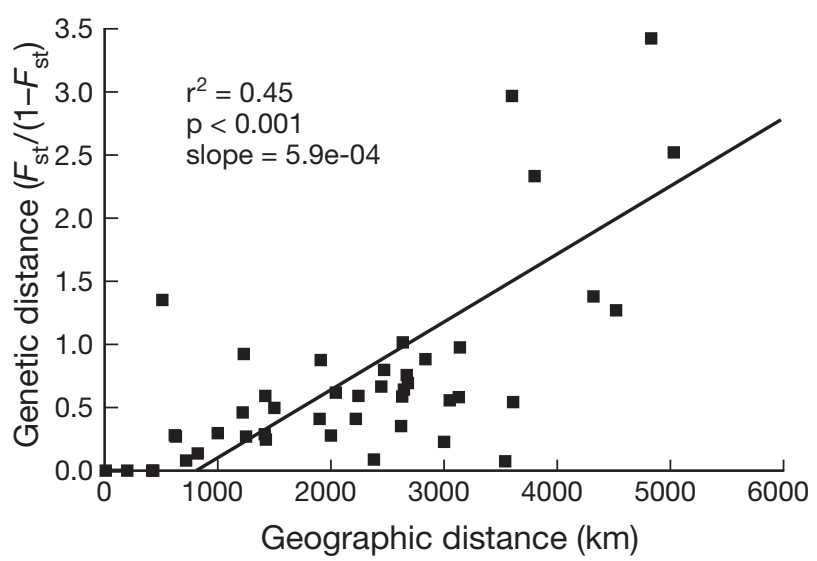

Fig. 2. Polydactylus macrochir. Mantel test of isolation by distance analysis, with coefficient of determination $\left(\mathrm{r}^{2}\right)$, associated p-value, and slope were not as genetically similar as samples collected from consecutive years from the same locations. Therefore, while most locations seem to have maintained their genetic identities over $10 \mathrm{yr}$, subtle changes in haplotype frequency have also occurred. Populations of the EGoC did not show spatial genetic structure in Years 1 and 2 (Table 2), or in the previous study of Chenoweth \& Hughes (2003). However, temporally EGoC samples were unstable, with $F_{\text {st }}$ values that were non-significant only after a strict Bonferroni adjustment of p-values (Table 3 ). Note that the Bonferroni adjustment is intended to safeguard against Type 1 error but is sometimes overly conservative because it also diminishes the power of the analysis (Moran 2003). Therefore, Bonferroni-corrected significance values should be interpreted cautiously. Further, while mostly not significant after Bonferroni adjustment, $F_{\text {st }}^{\prime}$ values were deep between the recent samples from the EGoC and the data of Chenoweth \& Hughes (2003) (Table 3). Temporal but not spatial genetic structure suggests that the genetic identity of the EGoC has changed over time as a unit and argues demographic interconnectivity between these populations.

\section{Historical demography}

The mismatch distributions of the entire data sets for both species were unimodal, which is indicative of demographic expansion (Figs. 3 \& 4). Fu's Fs value was significantly negative for both species $(-26.076$, $\mathrm{p}<0.0001$ and -26.602, $\mathrm{p}<0.0001$ for Polydactylus macrochir and Eleutheronema tetradactylum respectively), also indicating that demographic expansion 
Table 3. Polydactlyus macrochir. Temporal $F_{\text {st }}$ and standardized $F_{\text {st }}^{\prime}$ fixation indices of sampled populations from this study (vertical) against those of Chenoweth \& Hughes (2003) (horizontal), with corresponding p-values. Codes of regions and populations see Table 1. Significant values in bold; $p$-values < 0.0001 are shown as 0.0. $\mp$ : values not significant after Bonferroni correction $(\alpha=0.0004)$. Shaded areas indicate comparisons between populations in the same region. Italics indicate comparisons between samples from the same location

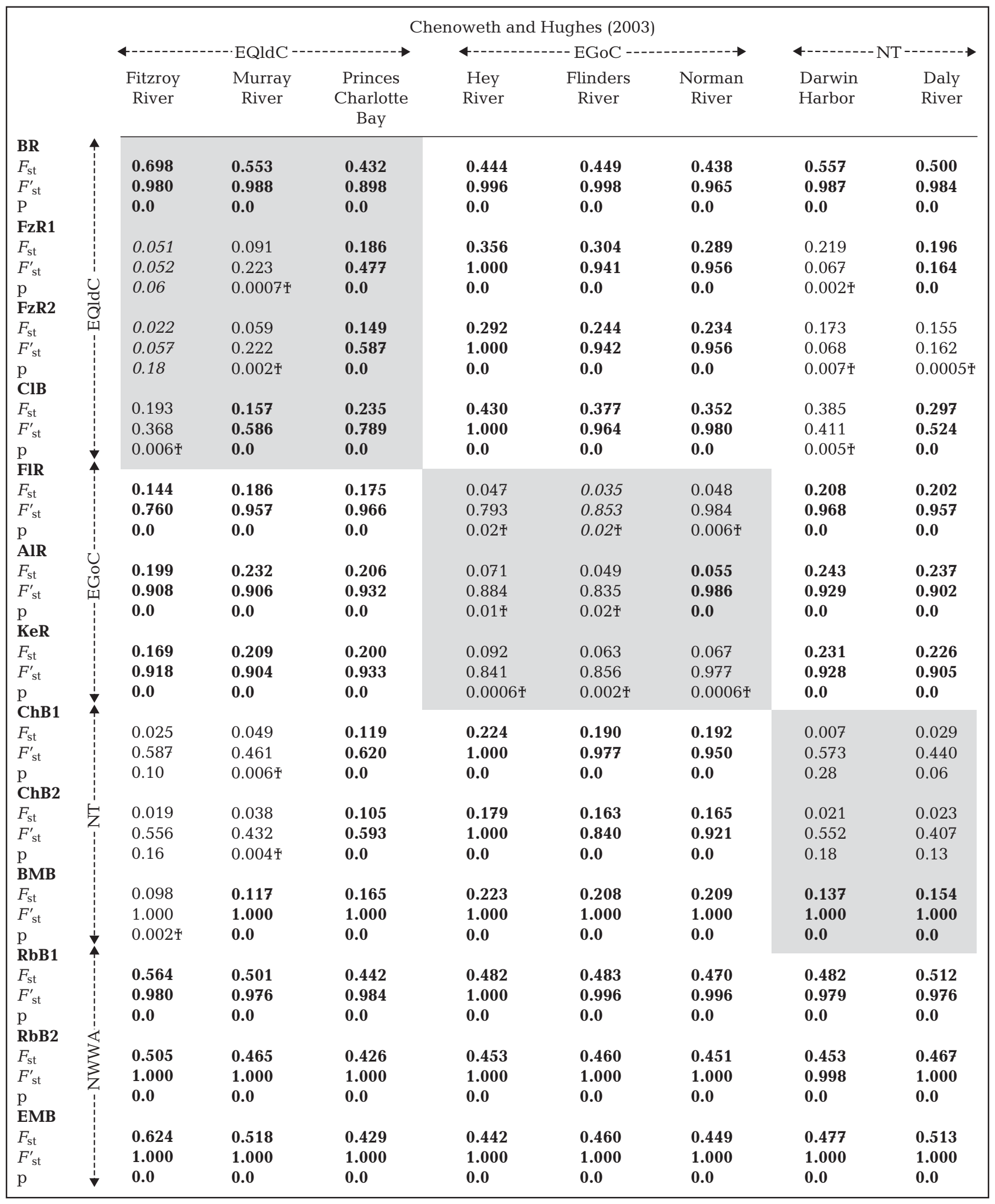


Polydactylus macrochir

Observed

Expansion model frequency

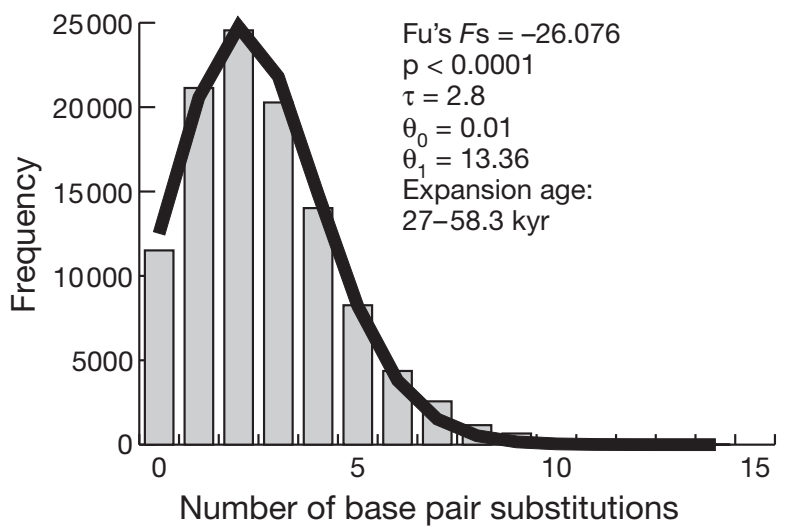

EQIdC
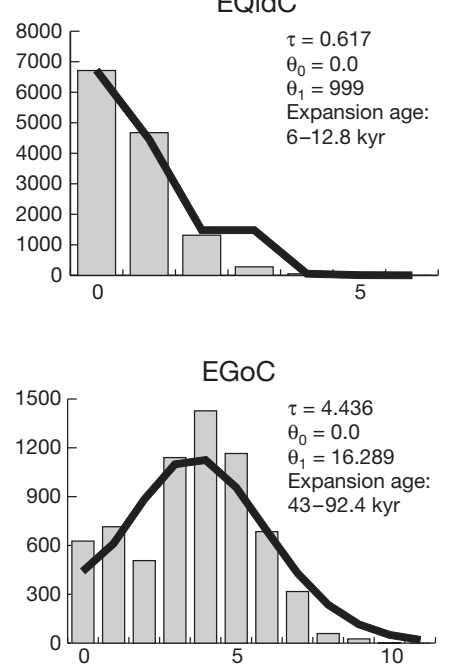

NT

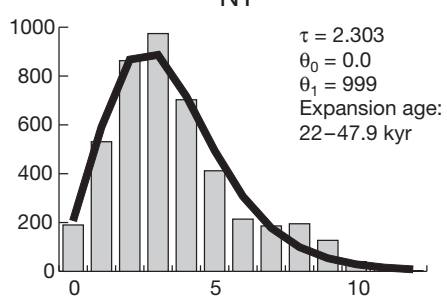

NWWA

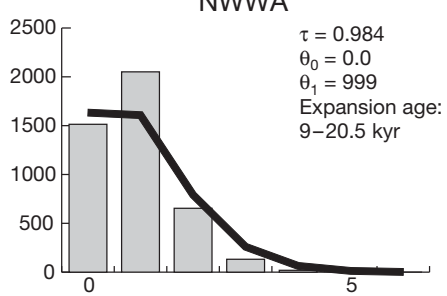

Fig. 3. Polydactylus macrochir. Mismatch distribution of 467 control region haplotypes (333 bp) and expansion model frequency, for the total sample (left) and by region (right). Region name codes are shown in Table 1. Values are shown for Fu's Fs test of population expansion, time since the onset of expansion in units of $2 u t(\tau)$ (see 'Materials and methods: Historical demography'), population size at the onset of expansion $\left(\theta_{0}\right)$ and at the present $\left(\theta_{1}\right)$, and expansion time in $10^{3} \mathrm{yr}(\mathrm{kyr})$. The ranges of expansion time are not confidence intervals but are due to different substitution rates $\left(\mu=1.9 \times 10^{-7}\right.$ to $\left.4.2 \times 10^{-7}\right)$

\section{Eleutheronema tetradactylum}

Observed

Expansion model frequency

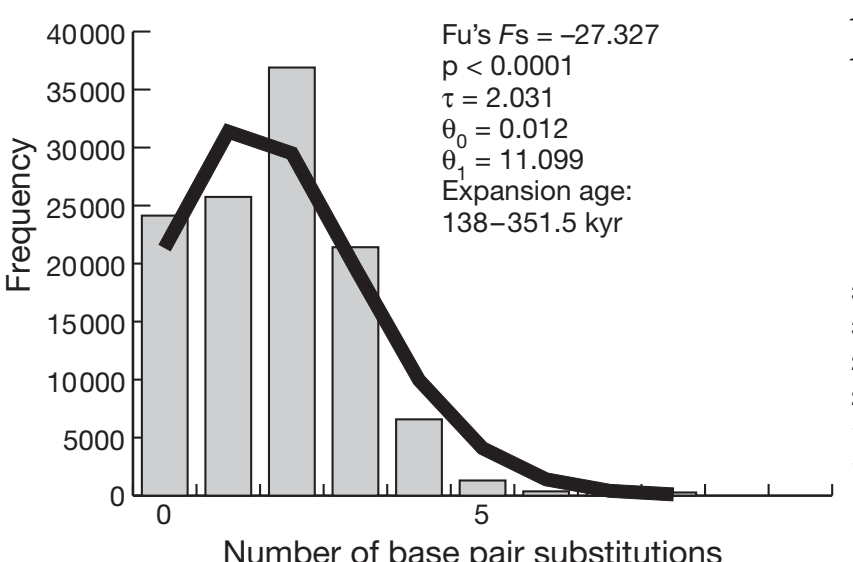

EQIdC

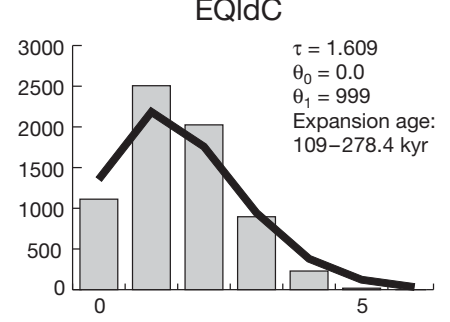

EGoC

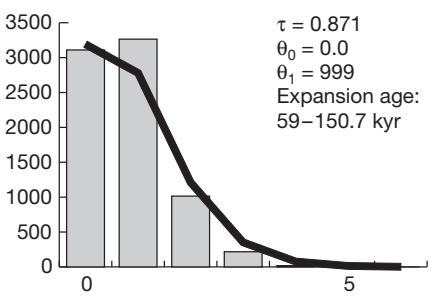

NT

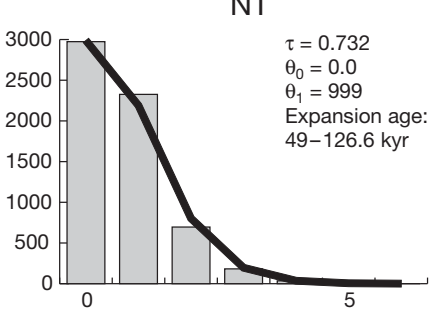

NWWA

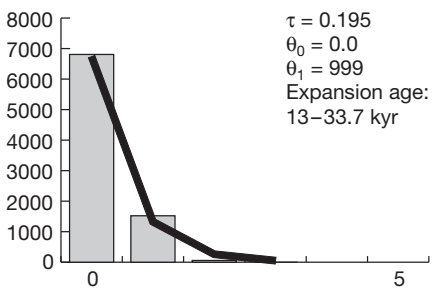

Fig. 4. Eleutheronema tetradactylum. Mismatch distribution of 485 COI haplotypes (628 bp) and expansion model frequency for the total sample (left) and by region (right). Region name codes are shown in Table 1. Values are shown for Fu's Fs test of population expansion, time since the onset of expansion in units of $2 u t(\tau)$ (see 'Materials and methods: Historical demography'), population size at the onset of expansion $\left(\theta_{0}\right)$ and at the present $\left(\theta_{1}\right)$, and expansion time in $10^{3} \mathrm{yr}(\mathrm{kyr})$. The ranges of expansion time are not confidence intervals but are due to different substitution rates $\left(\mu=1.1 \times 10^{-8}\right.$ to $\left.2.7 \times 10^{-8}\right)$

has occurred. Based on mismatch distributions, expansion in P. macrochir appears to be at least 5-fold younger than in E. tetradactylum: $27-58$ versus $138-352 \mathrm{kyr}$, respectively. Resulting mismatch distributions and neutrality tests from each region were also typical of population expansion (Figs. $3 \& 4$ ). In
P. macrochir expansion in the NT and EGoC commenced earlier than in NWWA or EQldC. In E. tetradactylum, the EQldC appears to have the oldest expansion time.

Independent runs of LAMARC yielded consistent results and inspection of LAMARC tracefiles in 
TRACER revealed ample effective sample sizes (>8000), smooth posterior distributions and had trace plots that were stable and characteristic of convergence. Effective mixing of the MCMCMC chains suggests that the parameter space was adequately explored and should add confidence to the inference in spite of the fact that a single marker is suboptimal in such analyses (Felsenstein 2006) and the high posterior density $95 \%$ confidence intervals were wide (Table 4). As with the mismatch based expansion times, coalescence age estimated in LAMARC indicated that Polydactylus macrochir genealogies were much shallower than Eleutheronema tetradactylum, with most probable coalescence ages of 13 and 29 kyr versus 100 and 250 kyr respectively, depending on what value of $\mu$ is used (Table 4). LAMARC was also used to analyze population history at a smaller regional scale but determining how to partition the data for this required some consideration. LAMARC assumes that populations have reached drift-migration equilibrium (which we presume at larger spatial scales, in spite of recent expansion, given significant IBD; Slatkin 1993) and that separate populations exchange migrants at a stable rate and have done so for a 'long time' (Kuhner 2009). LAMARC also struggles when $>\sim 3$ populations are considered (Kuhner 2009). Deciding how to appropriately divide the data for analysis in LAMARC was largely a matter of trial and error and several different configurations were tried. In the end, populations were analyzed as west (NWWA) and east (all other samples), in a 2 population migration matrix, in accordance with the strong pairwise fixation indices exhibited by both species against NWWA populations. Assignment tests of microsatellite loci for $E$. tetradactylum also support this break (Horne et al. 2011). Under this arrangement LAMARC performed well. In both species, populations of NWWA were estimated to be younger than their eastern counterparts, with most probable coalescence ages of 4 to $9 \mathrm{kyr}$ and 14 to $35 \mathrm{kyr}$ in P. macrochir and E. tetradatylum respectively. In the east, the most probable coalescence ages were 11 to $25 \mathrm{kyr}$ and 57 to $142 \mathrm{kyr}$ respectively (Table 4 ).

\section{DISCUSSION}

\section{Spatial and temporal genetic structure of Polydactylus macrochir}

Considerable genetic structure was detected throughout the geographic range of Polydactylus macrochir (Table 2). Along the EQldC, structure was detected between the Brisbane River, Fitzroy River and Cleveland Bay. In addition, the Princess Charlotte Bay samples from Chenoweth \& Hughes (2003) were also significantly structured against all other populations (Table 3). Within the Gulf of Carpentaria, significant structure was detected between

Table 4. Polydactylus macrochir and Eleutheronema tetradactylum. Bayesian coalescent simulations of historical demographic parameters with the $95 \%$ limits of the posterior distributions in parenthesis, for all samples and for pooled samples from western (NWWA) and eastern (all other samples) regions. $M$ : effective immigration rate expressed as immigration rate divided by $\mu_{i} \Theta$ : effective female population size expressed as $N_{\mathrm{e}} \mu$ estimated assuming unconstrained growth (above) and constant population size (c) (below); $g$ : exponential growth parameter; $\mu$ : substitution rate per site per generation

\begin{tabular}{|c|c|c|c|c|c|}
\hline & $M$ & $\Theta$ & $g$ & $\mu$ & $\begin{array}{c}\text { Coalescence age } \\
\text { (kyr) }\end{array}$ \\
\hline \multicolumn{6}{|l|}{ P. macrochir } \\
\hline All samples & & $\begin{array}{r}0.183(0.06-1.53) \\
\text { c } 0.023(0.01-0.04)\end{array}$ & $825(364-1682)$ & $\begin{array}{l}4.2 \times 10^{-7} \\
1.9 \times 10^{-7}\end{array}$ & $\begin{array}{l}13.3(6.5-30.1) \\
29.0(14.2-65.7)\end{array}$ \\
\hline East & $\begin{array}{l}21.4(0.03-87.3) \\
\text { East } \rightarrow \text { West }\end{array}$ & $\begin{array}{c}0.113(0.04-1.0) \\
\text { C } 0.017(0.009-0.03)\end{array}$ & $968(410-2122)$ & $\begin{array}{l}4.2 \times 10^{-7} \\
1.9 \times 10^{-7}\end{array}$ & $\begin{array}{l}11.3(5.2-26.7) \\
24.7(11.2-58.4)\end{array}$ \\
\hline West & $\begin{array}{l}94.7(1.8-347.5) \\
\text { West } \rightarrow \text { East }\end{array}$ & $\begin{array}{c}0.028(0.01-0.45) \\
\text { c } 0.003(0.001-0.007)\end{array}$ & 2634 (1258-4860) & $\begin{array}{l}4.2 \times 10^{-7} \\
1.9 \times 10^{-7}\end{array}$ & $\begin{array}{l}4.2(2.3-8.7) \\
9.1(4.9-19.0)\end{array}$ \\
\hline \multicolumn{6}{|c|}{ E. tetradactylum } \\
\hline All samples & & $\begin{array}{l}0.234(0.07-1.6) \\
\text { c } 0.02(0.01-0.03)\end{array}$ & $1694(514-3388)$ & $\begin{array}{l}2.7 \times 10^{-8} \\
1.1 \times 10^{-8}\end{array}$ & $\begin{array}{l}100.4(50.3-332.0) \\
246.5(123.6-815.0)\end{array}$ \\
\hline East & $\begin{array}{l}9.49(0-16.3) \\
\text { East } \rightarrow \text { West }\end{array}$ & $\begin{aligned} & 0.248(0.06-2) \\
& \text { c } 0.005(0.002-0.009)\end{aligned}$ & 2941 (1326-4873) & $\begin{array}{l}2.7 \times 10^{-8} \\
1.1 \times 10^{-8}\end{array}$ & $\begin{array}{r}58.0(35.0-128.6) \\
142.3(85.9-315.6)\end{array}$ \\
\hline West & $\begin{array}{l}10.35(0-15.9) \\
\text { West } \rightarrow \text { East }\end{array}$ & $\begin{array}{c}0.114(0.02-0.73) \\
\text { c } 0.0008(0.0001-0.002)\end{array}$ & $11990(8236-14857)$ & $\begin{array}{l}2.7 \times 10^{-8} \\
1.1 \times 10^{-8}\end{array}$ & $\begin{array}{l}14.2(11.5-28.2) \\
34.9(28.2-50.8)\end{array}$ \\
\hline
\end{tabular}


Blue Mud Bay, in the western gulf, and EGoC samples. With the exception of a few anomalous populations, such as Cleveland Bay, in which only the most common haplotype was sampled, and the NT populations, which for unknown reasons were weakly structured against the Fitzroy River, the signal of IBD in the data was unmistakable. These findings are harmonious with 2 other studies, performed on the same specimens used in the present study, one examining otolith microchemistry (Newman et al. 2010) and the other spatial variation in age and growth (Moore et al. 2011). Both studies conclude that movement between adjacent populations is limited. All indications suggest that most P. macrochir populations are largely self-seeding and that dispersal distances are small.

Temporally the genetic patterns of Polydactylus macrochir are mostly stable across the time period of a decade and the general results of Chenoweth \& Hughes (2003) were in large measure replicated by this study. However, the extent of temporal genetic homogeneity observed in samples from the same locations was not the same between the 1-yr and 10 -yr temporal scales, with the latter bordering on statistically significant genetic structure in many cases (Table 3). Although the genetic differentiation between temporal scales is subtle, other genetic studies of fishes have suggested that small differences in $F_{\mathrm{st}}$ can represent biologically important restrictions to gene flow rather than just noise in the data (Eble et al. 2009, Knutsen et al. 2011). In general, there are 2 factors that could account for temporal genetic structure: (1) Genetic drift. Small and insular breeding populations, as may be the case here, will naturally be more susceptible to the effects of random genetic drift than larger populations (Slatkin 1987), especially in the mtDNA which has a smaller effective population size than nuclear genes (Birky et al. 1989). Moreover, because in many areas $P$. macrochir appears to be at least fully exploited by fisheries (Pember et al. 2005), fishing pressure may potentially contribute to the effects of genetic drift. (2) Migration. While genetic drift cannot be overlooked as a force driving temporal population structure, fluctuations in local haplotype frequencies through some level of migration between local populations can lead to temporal genetic changes.

The degree of temporal genetic structure was not the same for all regions. In the $\mathrm{EGoC}$, temporal structure was much deeper than seen in other populations and was mostly significant before a Bonferroni adjustment of p-values (Table 3 ). Why the temporal genetic structure of the $\mathrm{EGoC}$ is less stable than other areas is not readily apparent. Plausibly, fishing pressure in the Gulf could have a greater impact than elsewhere. In this regard, it is noteworthy that a recent age-based study of Polydactylus macrochir, by Welch et al. (2010), reported a dramatic decrease in maximum age and an increase in the length-at-age relationship in the Gulf of Carpentaria compared to an earlier study by Bibby \& McPherson (1997). Such age-based patterns are most likely density dependent and temporal changes are arguably the result of fishing activity over the last $10 \mathrm{yr}$. Therefore, temporal genetic structure in Gulf populations of $P$. macrochir may be due to intensified genetic drift, in response to fishing pressure.

Additionally, temporal genetic instability in the gulf could be partly because EGoC populations experience more gene flow than other populations, as spatially there was no spatial population structure detected in the EGoC in this study or in Chenoweth \& Hughes (2003). Furthermore, temporal but not spatial genetic structure indicates that the change in genetic signature in these populations has occurred as a unit over time, suggesting demographic interdependence between them. Demographic connectivity in the $\mathrm{EGoC}$ could be enhanced due to seasonal ocean currents that develop in the Gulf. Motomura (2004) reports that spawning in Polydactylus macrochir occurs during the summer months, which coincides with wind driven, shore-parallel, ocean circulations in the Gulf of Carpentaria (Wolanski 1993). Year-class strength in juvenile $P$. macrochir has also been tied to rainfall and riverine output (Halliday et al. 2008), which is highest during summer months in the Gulf (Wolanski 1993). Therefore, spawning in P. macrochir appears to occur in sync with optimal conditions for larval dispersal in the Gulf of Carpentaria. Adult migration may also occur in the gulf, where 1 marked female was recaptured at a distance of $\sim 600 \mathrm{~km}$ (Welch et al. 2010).

Demographically significant gene flow in EGoC populations of Polydactylus macrochir appears to be exceptional, however, because most temporally sampled populations have retained their spatial genetic structure much better than those in the gulf. Therefore, while some migration between populations is likely to have occurred, causing temporal genetic changes, spawning site fidelity by adults and selfrecruitment by larvae appear prevalent in this species in most areas. From a fisheries management perspective, most populations of $P$. macrochir should be presumed to have a high degree of demographic autonomy. 


\section{Historical demography}

Polydactylus macrochir and Eleutheronema tetradactylum are very similar large inshore marine fishes with similar reproductive biology, habitat preferences and dietary ecologies (Motomura 2004). The spatial genetic patterns of P. macrochir and E. tetradactylum are also very similar: both species exhibit a phylogeographic break between NWWA and the rest of the tropical Australian coast and both species show finer scale population structuring within the geographic regions surveyed. Ecological and phylogeographic similarities are so striking that parallel demographic histories almost seem an inevitable conclusion. In spite of this, our results suggest that populations of E. tetradactylum are much older than equivalent populations of $P$. macrochir. If so, there may be some key ecological differences between the species.

It might be argued that the values of $\mu$ used in this study are arbitrary, and this may have led to a flawed analysis. Erroneous substitution rates are entirely possible because the rates used are either not based on geological calibrations or come from unrelated taxa. However, recall that we sequenced 18 Polydactylus macrochir individuals, from across northern Australia, at the COI locus and found no polymorphisms (see Materials and methods), not even between the most distant regions, NWWA and the EQldC. In contrast, 47 different haplotypes were identified in the COI locus in Eleutheronema tetradactylum, as well as a strong geographic signal in the data (Horne et al. 2011). Seemingly, P. macrochir is either too young to have acquired many mutations in the more conserved COI gene region, or has recently experienced a mitochondrial selective sweep (Meiklejohn et al. 2007). Nevertheless, while circumstantially a lack of COI polymorphism in P. macrochir suggests that mitochondrial coalescence in this species is indeed shallower, it does not conclusively demonstrate that the values of $\mu$ are accurate. Other selective processes that differ between the 2 mtDNA markers could also undermine the results of this study (see Haney et al. 2010). But, as Hickerson \& Meyer (2008) explain, if strong positive selection occurs on a marker before population expansion, estimates of coalescence age would be improved due to a loss of ancestral polymorphism.

The substitution rate $\mu$ is also dependent on generation time. For Eleutheronema tetradactylum we used an estimated average female generation time (4.5 yr) based on age at first and last female reproduction. In Polydactylus macrochir a female genera- tion time of 5 yr was used. This generation time was used for direct comparison with Chenoweth \& Hughes (2003). Yet, realistically, given a maximum potential longevity of over $20 \mathrm{yr}$ in some areas, the average female generation time of $P$. macrochir may be longer. Even so, increasing the generation time would not drastically alter our conclusions because assuming a longer generation time would only give an increased estimate of $\mu$ (per site substitution rate $x$ generation time), which cancels out for mismatch expansion age $(t=(\tau / 2 u) \times$ generation time), but would give $P$. macrochir an even more recent coalescence age than is presented here based on estimates of $g$.

In spite of substitution rates that are unsubstantiated and coalescence that is based on a single mtDNA marker, shallow coalescence age in Polydactylus macrochir could be explained by a population bottleneck at the most recent glacio-eustatic low in sea level $\sim 17 \mathrm{kyr} B P$, when sea level dropped $120 \mathrm{~m}$ below present levels (Bintanja et al. 2005, Wright et al. 2009). Low-sea-level population bottlenecks are expected and have been reported for fishes that are shallow water specialists (Fauvelot et al. 2003, Craig et al. 2010), due to loss of habitat. During the most extreme low-stands in sea level the geomorphology of the Australian coast undergoes dramatic transformations and shallow inshore habitat becomes scarce. On the east coast receding sea levels would have exposed the edge of the continental shelf, resulting in sea cliffs along much of what is now the Great Barrier Reef (Hopley et al. 2007). The Gulf of Carpentaria would have been dry land (Voris 2000). On the west coast the story would have been much the same (Twiggs \& Collins, 2010). Under these conditions it is unlikely that either species could have maintained large populations. But the population bottleneck seems to have been more acute in $P$. macrochir.

If Polydactylus macrochir is more sensitive to fluctuations in sea level it may be because it has more stringent habitat requirements than Eleutheronema tetradactylum. Plausibly, P. macrochir may be more dependent on estuaries as it is more frequently encountered in estuarine habitat (D. J. Welch pers. obs.) than E. tetradactylum. The larvae of P. macrochir also appear to settle exclusively in estuaries (Halliday et al. 2008), while E. tetradactylum larvae do not have a strict settlement habitat (M. Pember pers. comm.). Voris (2000) points out that during extreme lows in sea level a large river emptied from the Sahul shelf into the Arafura Sea. Speculatively, the estuary of this river could have been a low-sea-level refugium 
for $P$. macrochir, perhaps even the only refugium. If so, recolonization of the geographic range of $P$. macrochir could have been staged from this refuge, which might explain the much higher genetic diversity in NT and EGoC relative to NWWA and the EQldC, the latter of which was probably not colonized until after the Torres Strait was opened $\sim 7 \mathrm{kyr}$ BP (Hopley et al. 2007) (Fig. 3).

For Eleutheronema tetradactylum, the greatest genetic diversity was on the EQldC, in both mtDNA and nuclear microsatellites (Horne et al. 2011). EQldC also had the oldest regional expansion time. Potentially, recolonization of the north Australian coast could have spread from an eastern refugium in E. tetradactylum. However, this seems unlikely for at least 2 reasons: (1) E. tetradactylum lineages do not have as shallow a coalescence time and do not coalesce to around the time of the most recent glacial maximum. For recolonization to have come from the east, E. tetradactylum populations west of the Torres Strait would need to be younger than $\sim 7 \mathrm{kyr}$, which is inconsistent with our inferences. (2) Unlike Polydactylus macrochir, E. tetradactylum is not an Australian plate endemic and is found in waters throughout Southeast Asia. It is possible there has been some genetic communication between Australia and populations further north since the last glacial maximum. Most likely, E. tetradactylum fared better during times of low-sea-level and had multiple refugia, including an EQldC refugium that has since retained a unique genetic signature in the face of admixture.

\section{Peripheral isolation}

For reasons that are not evident, the west coast of Australia may have been entirely recolonized following sea level recovery, as coalescence ages of NWWA populations of both species are very shallow and indicate a late Pleistocene or Holocene recolonization by a small number of founders. In this regard both coalescence methods used in this study agree, placing the age of genetically depauperate NWWA polynemid populations within the last $20 \mathrm{kyr}$. Low genetic diversity is probably also due to limited migration, as well as recent recolonization: being on the westernmost periphery of the Australian coast means that opportunities for migrant exchange and the accumulation of genetic diversity are not as great as more centralized populations (Ray et al. 2003). The same can be said for the far eastern periphery on the EQldC, where the Brisbane River, had the lowest diversity of any Polydactylus macrochir population, ex- cept for Cleveland Bay. A combination of peripheral isolation and perhaps a narrow migration corridor along the Kimberly Coast best explains the genetic distinctiveness of NWWA polynemid populations.

\section{CONCLUSIONS}

Across northern Australia populations of Polydactylus macrochir are genetically fragmented and seem to have limited demographic interdependence, with the possible exception of EGoC populations, which apparently comprise a single demographic unit. Distance appears to be the greatest factor determining the amount of genetic exchange between populations, although the Kimberly Coast in NWWA and the Torres Strait in Queensland are probably also narrow migration corridors that may restrict gene flow. From a policy perspective, fisheries management of $P$. macrochir is recommended at the smallest spatial scale. Fisheries managers should also consider the temporal genetic heterogeneity in the EGoC, as this is potentially a reflection of intense fishing pressure. Extremely shallow mitochondrial coalescence suggests that this species has recently undergone a severe population bottleneck that corresponds to a loss of shallow water habitat around Australia during lowstands in sea level. Hence, P. macrochir appears more vulnerable to habitat disturbances than the co-distributed Eleutheronema tetradactylum of the same family, at least during some phases of its life cycle, and this should be a consideration for the fisheries management of this species. In particular, anthropogenic impacts, such as water infrastructure have been predicted to have adverse effects on P. macrochir populations (Halliday et al. 2008). The data presented here also suggests sensitivity to changes in habitat in this commercially important fish.

Acknowledgements. We thank the following people for their contributions to this paper: Aaron Ballagh for coordinating sample collections from the different locations, Brad Moore for Brisbane River samples, Stephen Chenoweth and Jane Hughes for collaborating data and information, Matt Pember for information on in situ observations, Giacomo Bernardi for methodological consultations and 4 anonymous reviewers for comments on the manuscript. We also thank the James Cook University Molecular Ecology and Evolution Lab. The authors are grateful to the inshore net fishers of Western Australia, the Northern Territory and Queensland for assistance in obtaining threadfin samples. This research was made possible by funding from the Fisheries Research and Development Corporation (Project No. 2007/032), a branch of the Australian Government Department of Primary Industries. 


\section{LITERATURE CITED}

Avise JC (2000) Phylogeography: the history and formation of species. Harvard University Press, Cambridge, MA

Bermingham E, McCafferty SS, Martin AP (1997) Fish biogeography and molecular clocks: perspectives from the Panamanian Isthmus. In: Kocher TD, Stepien CA (eds) Molecular systematics of fishes. Academic Press, San Diego, CA, p 113-118.

Bibby JM, McPherson (1997) Age and growth of five target fish species in the Gulf of Carpentaria inshore gillnet fishery. In: Garrett RN (ed) Biology and harvest of tropical fishes in the Queensland Gulf of Carpentaria gillnet fishery. Final Report No. 92/145, Fisheries Research and Development Corporation. Queensland Department of Primary Industries, Brisbane

Bintanja R, van de Wal RSW, Oerlemans J (2005) Modelled atmospheric temperatures and global sea levels over the past million years. Nature 437:125-128

Birky CW, Fuerst P, Maruyama T (1989) Organelle gene diversity under migration, mutation and drift: equilibrium expectations, approach to equilibrium, effects of heteroplasmic cells and comparison to nuclear genes. Genetics 121:613-627

Chenoweth SF, Hughes JM (2003) Oceanic interchange and nonequilibrium population structure in the estuarine dependent Indo-Pacific tasselfish, Polynemus sheridani. Mol Ecol 12:2387-2397

Clement M, Posada D, Crandall KA (2000) TCS: a computer program to estimate gene genealogies. Mol Ecol 9: 1657-1659

Cowen RK, Sponaugle S (2009) Larval dispersal and marine population connectivity. Annu Rev Mar Sci 1:443-466

Cowen RK, Gawarkiewicz G, Pineda J, Thorrold SR, Werner FE (2007) Population connectivity in marine systems: an overview. Oceanography (Wash DC) 20:14-21

Craig MT, Eble JA, Bowen BW (2010) Origins ages and population histories: comparative phylogeography of endemic Hawaiian butterfly fishes. J Biogeogr 37:2125-2136

Eble JA, Toonen RJ, Bowen BW (2009) Endemism and dispersal: comparative phylogeography of three surgeonfishes across the Hawaiian archipelago. Mar Biol 156: 689-698

Excoffier L, Lischer HEL (2010) Arlequin suite ver 3.5: a new series of programs to perform population genetics analyses under Linux and Windows. Mol Ecol Resour 10: 564-567

Fauvelot C, Bernardi G, Planes S (2003) Reductions in the mitochondrial DNA diversity of coral reef fish provide evidence of population bottlenecks resulting from Holocene sea-level change. Evolution 57:1571

Felsenstein J (2006) Accuracy of coalescent likelihood estimates: Do we need more sites, more sequences or more loci? Mol Biol Evol 23:691-700

Fu YX (1997) Statistical tests of neutrality of mutations against population growth, hitchhiking and background selection. Genetics 147:915-925

Hall TA (1999) BioEdit: a user-friendly biological sequence alignment editor and analysis program for Windows 95/98/NT. Nucl Acid S 41:95-98

> Halliday IA, Robins JB, Mayer DG, Staunton-Smith J, Sellin MJ (2008) Effects of freshwater flow on the year-class strength of a non-diadromous estuarine finfish, King threadfin (Polydactylus macrochir), in a dry-tropical estuary. Mar Freshw Res 59:157-164
Haney RA, Silliman BR, Rand DM (2010) Effects of selection and mutation on mitochondrial variation and inferences of historical population expansion in a Caribbean reef fish. Mol Phylogenet Evol 57:821-828

Hauser L, Carvalho GR (2008) Paradigm shifts in marine fisheries genetics: ugly hypotheses slain by beautiful facts. Fish Fish 9:333-362

> Hedgecock D, Barber PH, Edmands S (2007) Genetic approaches to measuring marine connectivity. Oceanography (Wash DC) 20:70-79

Hellberg ME (2006) Genetic approaches to understanding marine metapopulation dynamics. In: Kritzer JP, Sale PF (eds) Marine metapopulations. Academic Press, London, p 413-455.

> Hellberg ME (2007) Footprints on the water: the genetic wake of dispersal among reefs. Coral Reefs 26:463-473

Hellberg ME (2009) Gene flow and isolation among populations of marine animals. Annu Rev Ecol Evol Syst 40: 291-310

Hellberg ME, Burton RS, Neigel JE, Palumbi SR (2002) Genetic assessment of connectivity among marine populations. Bull Mar Sci 70:S273-S290

> Hickerson MJ, Meyer CP (2008) Testing comparative phylogeographic models of marine vicariance and dispersal using a hierarchical Bayesian approach. BMC Evol Biol $8: 322$

Higgins DG, Thompson JD, Gibson TJ (1994) CLUSTAL W: improving the sensitivity of progressive multiple sequence alignment through sequence weighting, position-specific gap penalties and weight matrix choice. Nucleic Acids Res 22:4673-4680

Hopley D, Smithers SG, Parnell KE (2007) The geomorphology of the Great Barrier Reef: development, diversity and change. Cambridge University Press, Cambridge

Horne JB, Momigliano P, Welch DJ, Newman SJ, van Herwerden L (2011) Limited ecological population connectivity suggests low demands on self-recruitment in a tropical inshore marine fish (Eleutheronema tetradactylum: Polynemidae). Mol Ecol 20:2291-2306

Jensen JL, Bohonak AJ, Kelley ST (2005) Isolation by distance, web service. BMC Genetics 6: 13 v.3.16. ibdws. sdsu.edu/

> Jones GP, Almany GR, Russ GR, Sale PF, Steneck RS, van Oppen MJH, Willis BL (2009) Larval retention and connectivity among populations of corals and reef fishes: history, advances and challenges. Coral Reefs 28: 307-325

Knowlton N, Weigt LA (1998) New dates and new rates for divergence across the Isthmus of Panama. Proc R Soc Lond B 265:2257-2263

> Knutsen H, Olsen EM, Jorde PE, Espeland SH, Andre C, Stenseth NC (2011) Are low but statistically significant levels of genetic differentiation in marine fishes 'biologically meaningful'? A case study of coastal Atlantic cod. Mol Ecol 20:768-783

Kritzer JP, Sale PF (2006) Marine metapopulations. Academic Press, London

Kuhner MK (2006) LAMARC 2.0: maximum likelihood and Bayesian estimation of population parameters. Bioinformatics 22:768-770

Kuhner MK (2009) Coalescent genealogy samplers: windows into population history. Trends Ecol Evol 24:86-93

Kuo CH, Avise JC (2005) Phylogeographic breaks in lowdispersal species: the emergence of concordance across gene trees. Genetica 124:179-186 
Leis JM, van Herwerden L, Patterson H (2011) Estimating connectivity in marine fish populations - What works best? Oceanogr Mar Biol 49:205-246

Librado P, Rozas J (2009) DNAsp v5: a software for comprehensive analysis of DNA polymorphism data. Bioinformatics 25:1451-1452

Lowe WH, Allendorf FW (2010) What can genetics tell us about population connectivity? Mol Ecol 19:3038-3051

Meiklejohn CD, Montooth KL, Rand DM (2007) Positive and negative selection on the mitochondrial genome. Trends Genet 23:259-263

Meyer A, Kocher TD, Basasibawaki P, Wilson AC (1990) Monophyletic origin of Lake Victoria cichlid fishes suggested by mitochondrial DNA sequences. Nature 347 : 550-553

Meirmans PG (2006) Using the AMOVA framework to estimate a standardized genetic differentiation measure. Evolution 60:2399-2402

Moore BR, Welch DJ, Simpfendorfer CA (2011) Spatial patterns in the demography of a large estuarine teleost: king threadfin, Polydactylus macrochir. Mar Freshw Res 62: 937-951

Moran MD (2003) Arguments for rejecting the sequential Bonferroni in ecological studies. Oikos 100:403-405

Motomura H (2004) Threadfins of the world (Family Polynemidae). An annotated and illustrated catalogue of polynemid species known to date. FAO species catalogue for fishery purposes 3. Food and Agriculture Organization, Rome

Motomura H, Iwatsuki Y, Kimura S, Yoshino T (2000) Redescription of Polydactylus macrochir (Gunther, 1867) a senior synonym of Polynemus sheridani (Macleay, 1884) (Perciformes: Polynemidae). Ichthyol Res 47:327-333

Newman SJ, Allsop Q, Ballagh AC, Garrett RN and others (2010) Variation in stable isotope $\left(\delta^{18} \mathrm{O}\right.$ and $\left.\delta^{13} \mathrm{C}\right)$ signatures in the sagittal otolith carbonate of king threadfin, Polydactylus macrochir across northern Australia reveals multifaceted stock structure. J Exp Mar Biol Ecol 396: 53-60

Palumbi SR, Martin A, Romano S, McMillan WO, Stice L, Grabowski G (1991) The simple fool's guide to PCR, version 2. University of Hawaii Zoology Department, Honolulu, $\mathrm{HI}$

Pember MB, Newman SJ, Hesp SA, Young GC, Skepper CL, Hall NG, Potter IC (2005) Biological parameters for managing the fisheries for blue and king threadfin salmons, estuary rockcod, Malabar grouper and mangrove jack in north-western Australia. Fisheries Research and Development Corporation Final Report No. 2002/003. Murdoch University, Perth

Planes S (2002) Biogeography and larval dispersal inferred from population genetic analysis. In: Sale PF (ed) Coral reef fishes: dynamics and diversity in a complex ecosystem. Academic Press, San Diego, CA

Posada D (2008) jModelTest: phylogenetic model averaging. Mol Biol Evol 25:1253-1256

> Pringle JM, Wares JP (2007) Going against the flow: maintenance of alongshore variation in allele frequency in a coastal ocean. Mar Ecol Prog Ser 335:69-84

Rambaut A, Drummond AJ (2007) Tracer v1.4. beast.bio.ed. ac.uk/Tracer

$>$ Ramos-Onsins SE, Rozas J (2002) Statistical properties of new neutrality tests against population growth. Mol Biol Evol 19:2092-2100

Ray N, Currat M, Excoffier L (2003) Intra-deme molecular diversity in spatially expanding populations. Mol Biol
Evol 20:76-86

Rogers AR, Harpending HC (1992) Population growth makes waves in the distribution of pairwise genetic differences. Mol Biol Evol 9:552-569

> Rousset F (1997) Genetic differentiation and estimation of geneflow from $F$-statistics under isolation by distance. Genetics 145:1219-1228

Selkoe KA, Henzler CM, Gaines SD (2008) Seascape genetics and the spatial ecology of marine populations. Fish Fish 9:363-377

Siegel DA, Mitarai S, Costello CJ, Gaines SD, Kendall BE, Warner RR, Winters KB (2008) The stochastic nature of larval connectivity among nearshore marine populations. Proc Natl Acad Sci USA 105:8974-8979

Slatkin M (1987) Gene flow and the geographic structure of natural populations. Science 236:787-792

Slatkin M (1993) Isolation by distance in equilibrium and nonequilibrium populations. Evolution 47:264-279

Small ST, Wares JP (2010) Phylogeography and marine retention. J Biogeogr 37:781-784

Twiggs EJ, Collins LB (2010) Development and demise of a fringing coral reef during Holocene environmental change, eastern Ningaloo Reef, Western Australia. Mar Geol 275:20-36

> Voris HK (2000) Maps of Pleistocene sea levels in Southeast Asia: shorelines, river systems and time durations. J Biogeogr 27:1153-1167

- Waples RS (1998) Separating the wheat from the chaff: patterns of genetic differentiation in high gene flow species. J Hered 89:438-450

Waples RS, Gaggiotti O (2006) What is a population? An empirical evaluation of some genetic methods for identifying the number of gene pools and their degree of connectivity. Mol Ecol 15:1419-1439

Waples RS, Punt AE, Cope JM (2008) Integrating genetic data into management of marine resources: How can we do it better? Fish Fish 9:423-449

> Ward RD, Zemlak TS, Ines BH, Last PR, Hebert PDN (2005) DNA barcoding Australia's fish species. Philos Trans R Soc B 360:1847-1857

> Wares JP, Cunningham CW (2001) Phylogeography and historical ecology of the north Atlantic intertidal. Evolution 55:2455-2469

Welch DJ, Gribble N, Garrett R (2002) Assessment of the threadfin salmon fishery in Queensland - 2002. Queensland Department of Primary Industries, Report No. QI02115, Northern Fisheries Centre, Cairns

Welch DJ, Garret RN, Gribble NA (2005) Fisheries uncertainty: a tropical Australian data-poor fishery. In: Kruse DH, Gallucci VF, Hay DE, Perry RI, Peterman RM (eds) Fisheries assessment and management in data-limited situations. Alaska Sea Grant College Program, Anchorage, AK, p 533-552

Welch DJ, Ballagh A, Newman SJ, Lester RJ and others (2010) Defining the stock structure of northern Australia's threadfin salmon species. Draft final report to the Fisheries Research \& Development Corporation, Project 2007/032. Fishing \& Fisheries Research Centre, James Cook University, Townsville

> Wolanski E (1993) Water circulation in the Gulf of Carpentaria. J Mar Syst 4:401-420

Wright JD, Sheridan RE, Miller KG, Uptegrove J, Cramer BS, Browning JV (2009) Late Pleistocene sea level on the New Jersey margin: implications to eustasy and deepsea temperature. Global Planet Change 66:93-99 